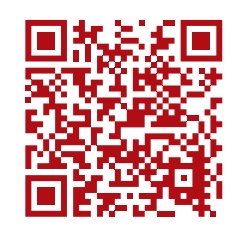

\title{
Las pandemias y el renacimiento
}

\author{
Pandemics and the renaissance
}

\section{Dra. Estela Vélez-Benítez,* Dr. Jesús A Cuenca-Pardo*}

«La muerte, que baila con todos los estamentos sociales, del obispo al emperador o el campesino»

(Danza de la muerte, género artístico tardo-medieval)

«Aprender del pasado para no cometer errores en el presente»

Klaus Feldmann Petersen

\begin{abstract}
$\mathrm{A}^{\mathrm{l}}$ lo largo de la historia de la humanidad han existido varias epidemias que no sólo han cobrado muchas vidas, sino que también han tenido severas repercusiones sociales y económicas. Una de las más devastadoras fue la Peste en el año 1347, momento de la mayor decadencia y de mayor crisis de la edad medieval; 48 millones de personas murieron directa o indirectamente a causa de esta enfermedad, ya fuera por contagio, por abandono o por falta de recursos básicos para su atención. El fenómeno social de la epidemia de peste tiene muchas similitudes con la pandemia de COVID-19 que nos ha tocado vivir.

La peste negra y el COVID-19 son enfermedades que se propagan rápidamente a través del contacto cercano y ocasionan una gran cantidad de muertes; han aparecido en época de crisis y han sorprendido a los gobiernos que no han estado preparados para resolver la magnitud del evento. La ineficacia de cómo se ha afrontado el problema ha costado muchas vidas y ha contribuido a exacerbar los problemas socioeconómicos de los países involucrados.

Ambas enfermedades no se conocían; el entendimiento de la misma se dio en el transcurso de la epidemia. Los principales protagonistas en el tratamiento de los enfer-
\end{abstract}

mos y en el control de la epidemia han sido los médicos. Los médicos del Medioevo se protegían usando una careta en pico de pájaro sobre una indumentaria especial; los médicos actuales nos cubrimos con goggles, caretas, overoles, etcétera. En ambos casos, los médicos han aceptado el riesgo del contagio. ¿El equipo de protección personal que se utiliza evita el contagio? ¿Ha habido suficientes equipos para todos los médicos y sus auxiliares?

Durante la peste se dieron varios fenómenos sociales; al iniciar la epidemia, las personas tendían a negarla hasta comprobar su impacto al ver que sus prójimos, incluyendo sus

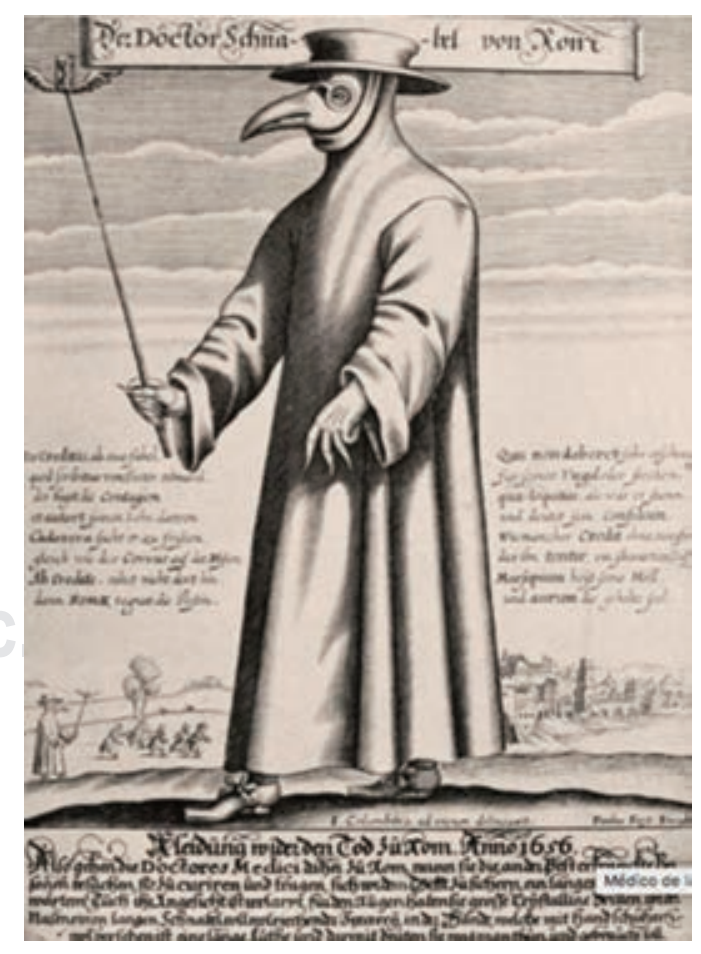


familiares, se estaban muriendo. Se llenaron de pánico y trataron de huir de las ciudades, favoreciendo la propagación de la epidemia; utilizaron rituales religiosos y al darse cuenta de que no funcionaban, se alejaron de las religiones. Muchas fuentes de trabajo dejaron de funcionar, favoreciendo la pobreza extrema y el hambre; la mayoría de los enfermos fueron abandonados por sus familiares. Al fallecer, no había quién los sepultara, la mayoría terminó en una fosa común. Respecto a la respuesta social, también encontramos grandes similitudes con la pandemia actual, desde la negación, que pasó después al pánico, huida, abandono de pacientes, racismo, xenofobia contra el personal sanitario, propagación de falsos rumores, lucro y otras conductas oportunistas.

Las contingencias por las epidemias que ha sufrido la humanidad han obligado a una superación técnica científica, con un cambio esencial en la mentalidad. Los sobrevivientes obtienen una conciencia de la existencia humana y de su inexorable destino. Después de la crisis se busca el aprovechamiento de los recursos para mejorar la existencia humana. En las ciudades más afectadas por la peste fue donde surgió un crecimiento cultural, el ser humano pasó a ser el centro de la filosofía y de la cultura general (antropocentrismo), desplazando a la iglesia y los pensamientos mágicos y religiosos. Este movimiento fue la base para el Renacimiento, época de prosperidad y superación humana, reflejada en el arte, la economía, la producción y la ciencia. En la medicina hubo grandes avances: un mayor entendimiento del cuerpo humano y de su fisiología, así como la formación de organismos sanitarios.

¿EI COVID-19 dará origen a un renacimiento? ¿La forma de vivir será la misma? ¿Qué enseñanza nos está dejando? ¿Lograremos mejorar como humanidad?

Durante la actual pandemia de COVID-19, se están dando los cambios en la humanidad con marcadas diferencias, al compararla con la peste. La pandemia se está enfrentando con una mayor tecnología y mayores recursos científicos. Los familiares no abandonan a sus enfermos y cuando lo hacen son obligados por las necesidades sanitarias, con el fin de evitar la propagación de la infección. Han surgido dentro del personal sanitario personas con empatía y altruismo que se han preparado para el cuidado y ayuda a los afectados. Ahora los responsables de resolver la crisis por la pandemia realizan un intercambio de experiencias y conocimientos con sus pares, a través de los medios de comunicación social, a una velocidad vertiginosa, lo que ha contribuido a entender en un corto tiempo la enfermedad y encontrar algunas soluciones en el manejo de los pacientes afectados. La población general recibe a través de los medios de comunicación social la información suficiente para conocer los cuidados sanitarios que prevengan la enfermedad o para disminuir su impacto. La pandemia de COVID-19 nos ha unido de manera universal, sin importar nacionalidad, creencia religiosa, partido político o idioma, con un solo fin: encontrar la mejor solución a la contingencia. La pandemia nos está enseñando que los sobrevivientes debemos cambiar nuestra forma de vivir y trabajar.

Varias asociaciones médicas en todo el mundo están preparando el regreso a las actividades rutinarias en condiciones diferentes a las acostumbradas. Las condiciones sanitarias de los consultorios, clínicas y hospitales se están mejorando, la evaluación y preparación preoperatoria se ha vuelto más estricta, las cirugías tendrán que realizarse con mayores cuidados y con la utilización de equipos de protección personal para todo el equipo quirúrgico. El personal médico deberá extremar sus condiciones de salud, aplicarse vacunas y realizarse exámenes periódicos para la detección de enfermedades transmisibles y para valorar sus condiciones de salud.

El renacimiento esperado posterior a la pandemia itendrá un impacto en los cirujanos plásticos y en sus pacientes? ¿Habrá un cambio en el número de procedimientos de cirugía plástica?

El tiempo de cuarentena nos ha obligado a reflexionar sobre nuestra práctica quirúrgica. Hemos podido valorar nuestros resultados y nuestros alcances; así también hemos proyectado cómo será nuestra práctica en el futuro. El tan esperado regreso a nuestras actividades laborales como cirujanos plásticos nos hará regresar con mucho entusiasmo, dispuestos a aceptar nuevos retos, aprovechar las oportunidades y mejorar nuestro actuar como cirujanos. En estos cambios no debemos olvidar la seguridad 
de nuestros pacientes, el personal del equipo quirúrgico con el que solemos trabajar deberá comprometerse en su cuidado, utilizando las guías y protocolos de seguridad ya establecidas, sólo así podremos llegar a los objetivos de icero complicaciones y cero muertes en los pacientes de cirugía plástica!, y ser un ejemplo para las demás especialidades.

Nuestros pacientes después de la crisis tendrán una conciencia superior sobre su existencia y van a tratar de aprovechar los recursos para mejorarla. $\mathrm{Al}$ igual que en la peste, habrá una marcada tendencia al antropocentrismo, condiciones que debemos ver como una oportunidad para ofrecer nuestros servicios y hacer entender a los pacientes que los procedimientos de la especialidad no son de vanidad y superfluos, sino que les serán de mucha utilidad para mejorar su imagen corporal y autoestima, condiciones necesarias en este nuevo renacer.

\section{LECTURAS RECOMENDADAS}

1. ¿Cómo cambió a Europa la Peste negra? Disponible en: www.lavanguardia.com > historia medieval.

2. De la muerte negra al renacimiento. La guía de la filosofía. Disponible en: Filosofia.laguia2000. com > general > de-la-muerte-negra.

3. Cómo se compara el número de muertes por coronavirus con otras pandemias, como el SARS, el VIH y la Peste Negra. Disponible en: https:// businessinsider.mx/como-se-compara-el-numero-demuertes-por-coronavirus-con-otras-pandemias-comoel-sars-el-vih-y-la-peste-negra/.

4. Expertos hablan de similitudes y diferencias del COVID-19 con pandemias históricas. Disponible en: https://www.aa.com.tr/es/mundo/expertos-hablande-similitudes-y-diferencias-del-covid-19-conpandemias-hist $\%$ C3\%B3ricas/1777840.

Correspondencia:

\section{Dra. Estela Vélez-Benítez}

Frontera Núm. 74-421,

Col. Roma Norte, 06700,

Alcaldía Cuauhtémoc,

Ciudad de México, México.

E-mail: cirugiaplastica@draestelavelez.com 